\title{
THE IDEAL FAIRYTALE: DIY CINDERELLA
}

\author{
Saeryn Ryu, Jun Hyung Lee and Hyun Bin Cho \\ Sogang University \\ Seoul, South Korea
}

\begin{abstract}
Programming was once considered as a high-level technique that only experts can handle, however, now the range of programmers has expanded to the general public, as coding is becoming a basic and popular skill. It can now work as a fundamental tool for everyone to express their creativity. Starting from a single program such as a smartphone app, a lot of small businesses have now developed their economic scales to the level of big conglomerates that influence the society as a whole. Besides the economic success that this technology can bring, it also has the potential to contribute to an educational aspect, which means it can have a great impact on how young children might be able to think in the future.

In this article, we suggest a program, or it can also be referred as a 'game,' that goes against the contents of conventional educational materials that has been used and is still being used by the society to educate young children. As three university undergraduates who were born and raised in South Korea, we developed a program that challenges the fixed contents and the fixed method of the previous educational material that we had been taught as children. We used Python to create the program and the name of the program is $<$ DIY Cinderella $>$, an acronym for "Do it Yourself Cinderella." Through making this program, we expect that children's education and entertainment can be made into more diverse content and forms.
\end{abstract}

\section{KEYWORDS}

Gender, Stereotype, Python, Fairytale, Game, Education

\section{INTRODUCTION}

In recent years there has been rising controversy regarding the issue of portrayal of gender within the media. For example, there have been criticism regarding the lack of diverse characters, or the questionable depictions of the way characters act according to gender. These are indeed serious issues, and of these various media and genres, fairy tales must receive proper attention because they are especially problematic. This is because, "fairy tales not only influence a child's moral development but also their ideas of appropriate gender conduct. These childhood texts 'represent 'internalized' formulas for social and by extension, gender behavior' (Haase and Primeau, 1993). Impressionable children absorb these lessons and begin to shape their own life around them" (Steinzeig, 2012). Considering the influence that can be implicated by such fairy tales, we came up with the question of: In what ways are fairy tales problematic in the portrayal of gender and how can we solve the issues they implicate?

After some research, we came to conclusion that fairy tales are problematic in the representation of gender and sexual orientation and the construction of gender roles. First, characters in fairy tales are overwhelmingly heterosexual, the reason for which, we found in the history of the genre. The earliest publications of collections of folk tales were by Charles Perrault or, Brothers Grimm, who were all from European countries that were Christian at the time, which explains the heterosexuality in the stories. Yet this is outdated and is detrimental in their effects on construction of views regarding sexual orientation and gender. Also, they reinforce several gender roles, shown in how, "the hero is generally characterised by his activity," while, "the heroine is usually pictured as more helpless" (Toomeos-Orglaan, 2013). These portrayals of the characters are influential in the development of children's perspectives regarding gender, and thus are in dire need of resolution.

The first idea we had was to choose a fairy tale, analyze their various problems and by fixing them, create the perfect fairy tale. However, while brainstorming stories to change and how to change them, we ran into a major obstacle. Can an ideal fairy tale truly exist? For example, with princess stories, we wanted to change the personality of the characters, so they would not be as helpless. We soon realized however, that though we intended to solve the problem of stereotyping women as weak, this in turn reinforced the notion that they should 
be strong. Instead of eradicating the gender role, it simply created a new, different one in its place. We therefore concluded that a correct answer does not exist and thus, neither does an ideal fairy tale.

Thus, we decided to focus on the concept of there being no correct answer. With no singular correct answer, only diversity is left. We realized that it was the idea of there being an ideal answer that was the cause of gender roles, when in reality, all outcomes have meaning. To build upon this idea we resolved to create a program of sorts, a kind of game, in which people could recreate fairy tales. This would not be an ideal fairy tale, but one that is distinct, and their own. Through this program, we aimed to help the participant realize that fairy tales could, without losing their original color, be changed to embody both contemporary and individual values in diverse ways. With this diversity, it would be possible to realize just how trapped we are within gender roles imposed on us by fairy tales we came to love when we were children and break free of them.

\section{WHY CINDERELLA?}

The fairy tale we decided to focus on was the Disney Cinderella. This was because the story itself embodies the aforementioned common issues of fairy tales in gender and is one of the most iconic fairy tales there are. The story of Cinderella has been criticized that "she is a sorry excuse for a heroine, pitiable and useless. She cannot perform even a simple action to save herself, though she is warned by her friends, the mice. She does not hear them because she is "off in a world of dreams"" (Yolen, 1977), and thus "suggests that a girl does not have to fight for the justice and she can let others hurt her feelings and treat her in a bad and inferior role. Everything a girl has to be is good and kind in any case" (Veselá, 2014). There are problems in the portrayal of men as well, in the, "emphasis on the hero's financial provision as even little girls are already guided to find a rich husband who will render them the necessary comfort that will secure their contentment" (Veselá, 2014). Considering these serious problems in the story, we thought it would be especially meaningful to handle the Disney Cinderella because of how iconic she is.

\section{THE FIXED AND VARIABLE ELEMENTS OF DIY CINDERELLA}

Table 1. Fixed elements and Variable elements of <DIY Cinderella $>$

\begin{tabular}{c|c}
\hline Fixed elements & Variable elements \\
\hline $\begin{array}{c}\text { Name of the main character } \\
\text { 'Cinderella' }\end{array}$ & $\begin{array}{c}\text { Gender and Sexual } \\
\text { Orientation }\end{array}$ \\
\hline $\begin{array}{c}\text { Stepfamily being jealous of } \\
\text { Cinderella }\end{array}$ & Course of events \\
\hline $\begin{array}{c}\text { Leaving behind a possession } \\
\& \text { returning home before } \\
\text { midnight }\end{array}$ & Details \\
\hline $\begin{array}{c}\text { Existence of Cinderella's } \\
\text { potential partner }\end{array}$ & \\
\hline
\end{tabular}

Determining what elements to fix or make variable was essential before creating our program and we have concluded as it shows in Table 1. Since there are many versions of Cinderella, we decided to keep fixed the common characteristics, so that that the recreation could be recognizable as a Cinderella story. "The structure seen in the stories based on Cinderella's topic can be divided as (...) the prosecuted heroine, magic help, meeting the prince, proof of identity, marriage of the prince" (Veselá, 2014). We fixed the elements of the persecuted heroine, magic help, proof of identity, and meeting the prince, although as the gender and sexual orientation of all characters were made variable, the terms 'heroine' or 'prince' are inappropriate. The last element of marriage was made variable because we did not want marriage to be the only means of "living happily ever after". In addition, characters' behavior and personality were also made variable so that the participants could change the passive Cinderella of the original story. Moreover, objective features of appearance (height and skin color rather than 'pretty' or 'ugly') were added as variable elements. This is because we wanted to include the visual factors, since our program's story was based on the Disney version of Cinderella, iconized by the animation. 


\section{WHY PYTHON?}

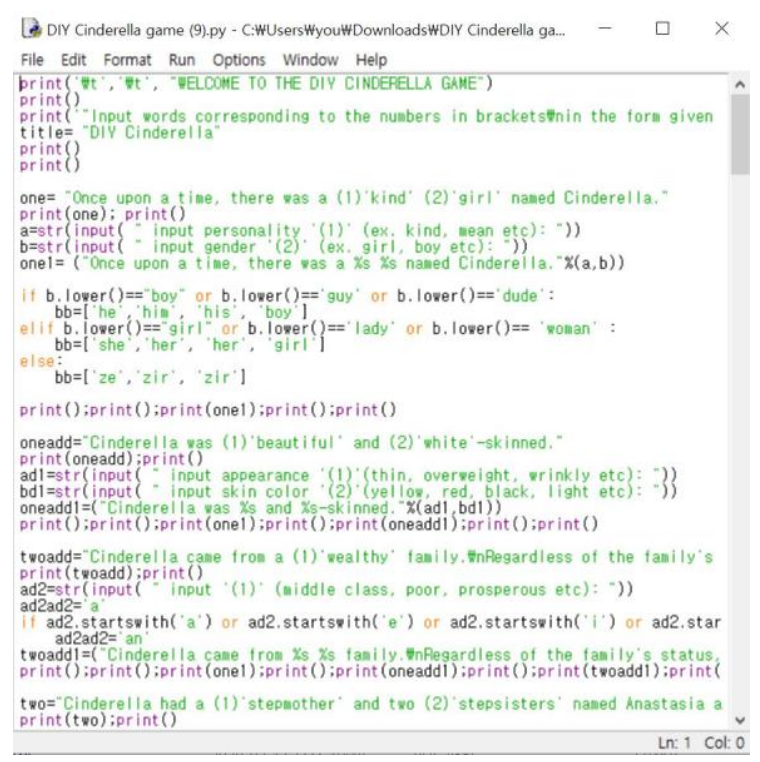

Figure 1. The Python Script of <DIY Cinderella>

As you can see in Figure 1, we utilized Python in order to make this program. Google and Naver surveys are the most common methods of gathering information when it comes to Korean University students' projects. However, we wanted people (children) to make the most individual and original version of Cinderella that suits their sexuality and sexual orientation. This led to a thought that we have to utilize programming system as our format in order to realize our intention of the whole project. Since Python was the only tool we were all familiar with, we chose to use Python as the platform for our program, despite its lack of accessibility in that the process of downloading Python program to participate in our program was relatively complicated.

\section{BRIEF MANUAL OF HOW <DIY CINDERELLA $>$ WORKS}

First, in order to use our program, you will have to install the Python program. After the install, the first screen you will get after clicking our program is the first page of our program, shown in Figure 2. The story will begin with the cliché fairytale opening of "Once upon a time..." and the user will be ready to fill in the blanks right away.

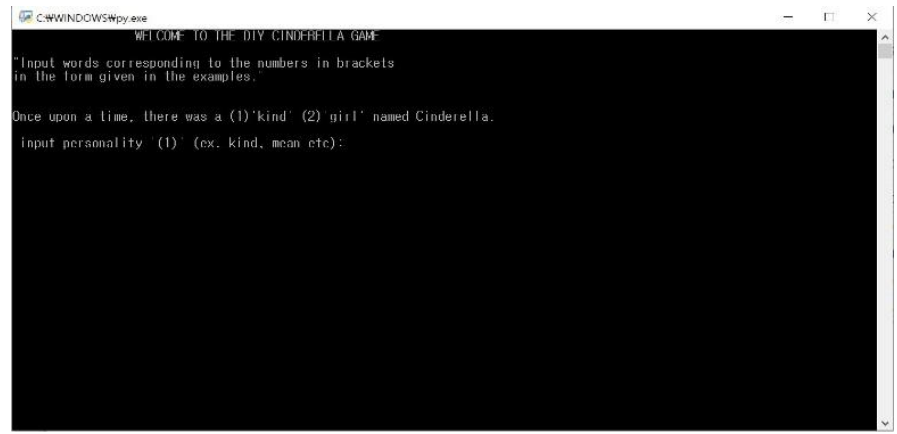

Figure 2. How the program appears when you first run it

Now you start to create and construct your own Cinderella story using different adjectives, pronouns, nouns, etc. Next, see Figure 3, which the red circles refer to the input of the user and the red underlines are how the user input is reflected to the storyline. 


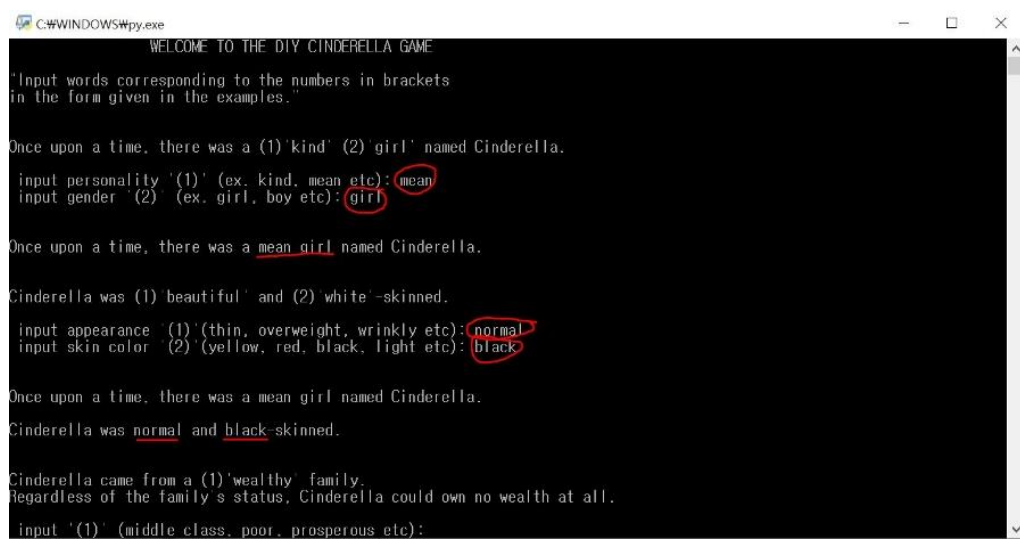

Figure 3. Process of running the program

If you input 'mean' instead of 'kind' the story reflects your input and starts to create the story with the words that you chose. Same way, in the next part, because the user inputted 'normal' and 'black' instead of the original words 'beautiful' and 'white,' the story changed from "Cinderella was beautiful and white-skinned" to "Cinderella was normal and black-skinned." This goes on with more than 20 inputs.

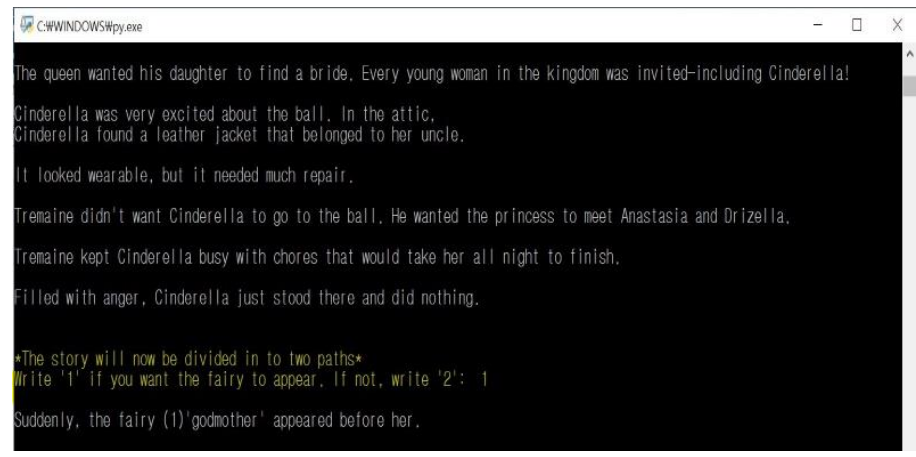

Figure 4. Part where the user can choose the path of the storyline

Not only the words, but we tried to make the program reflect more of the users' personality. In Figure 4, the program makes the user to choose whether the fairy should appear or not, which is the part where the fairy godmother appears in the original story. Since the fairy godmother basically does everything in the original story, Cinderella is criticized of being passive and submissive. Therefore, we included the fairy godmother scene as a variable element though it was first considered one of the most important fixed elements that symbolized the original Cinderella story. In other words, if you want your Cinderella to be more active and confident, you don't need to make the fairy appear in the story at all. This path-choosing scene appears once more in the last part of our program, which is the part where Cinderella loses one of her possessions (glass slipper in the original story). In the original one as everyone knows, Prince Charming make his servants find Cinderella. This part also shows how passive Cinderella is and how male characters tend to appear as the hero in all fairytales. We wanted to break the stereotype, so we made the users to choose whether they want their Cinderellas to be found or their Cinderellas finding their possessions by themselves. 


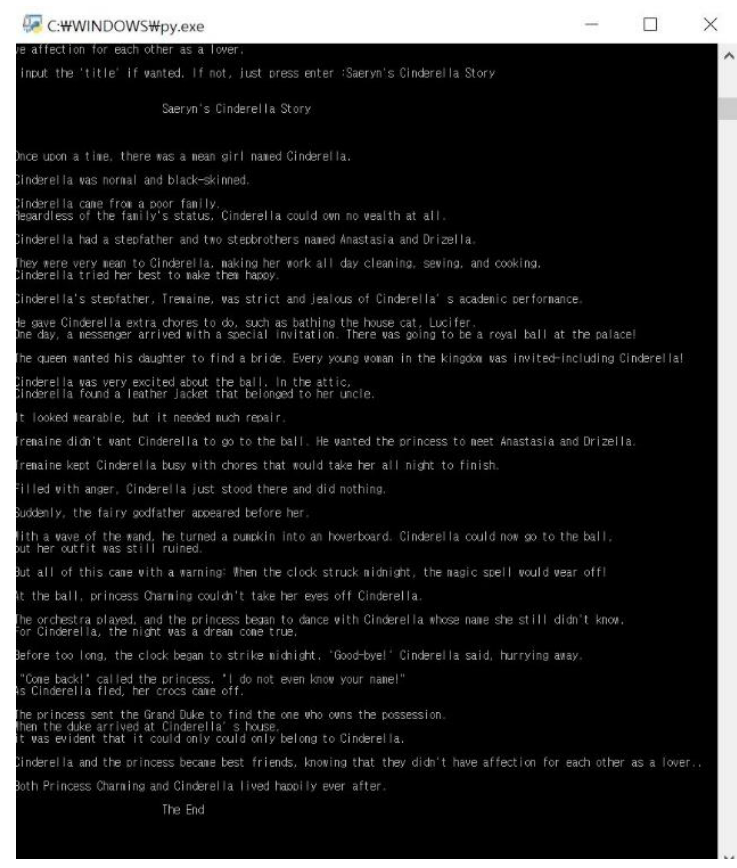

Figure 5. A completed version of $\langle$ DIY Cinderella $>$

The happily-ever-after ending is also a very common stereotypical ending of most fairytales. We felt that there should be no obligation for young children to feel that every relationship has to end happily and getting married, so we made the users to create their own ending. For example, in Figure 5, instead of Cinderella getting married to the Prince/Princess Charming, the story ends by saying "They became best friends, knowing that they didn't have affection for each other as a lover." Any kind of endings are possible, such as getting married but getting divorced shortly after.

\section{SHARING SESSION}

We uploaded mainly three things on the Facebook page Sogang Univ. and other several KakaoTalk chat rooms (National chatting app in South Korea). The DIY Cinderella game itself, the manual for the program and the Python download file. These are the materials required to play the game. Moreover, we also uploaded the link to an "Anonymous DIY Cinderella Chat Room", where people could share their own DIY Cinderella stories and exchange feedback on both the stories and the project itself. The chat room was created so that people could enjoy the game further and learn what other diverse choices people made. We created the DIY Cinderella Chat Room as we wanted something more to our project than just simply making and sharing the program.

Members in the chat room could largely be divided into "Readers" and "Writers. "Readers" were those who only read and responded to the stories of others, while "Writers" were those who not only read other's stories but also shared their own. We found that the participants seemed to enjoy playing the game along with reading others' stories even more than we anticipated. "Writers" showed the tendency of uploading multiple stories, proving their interest through repeated participation in the program.

The variety of stories uploaded constituted an incredibly wide spectrum. The variable words for describing Cinderella's gender were much more diverse in participants' stories than we originally imagined. "Girl", "boy", "guy", "bisexual", "MTFtransgender", are some examples of the wide spectrum of terms that were used. As expected, the binary gender terms were most often used. However, many people attempted to facilitate the usage of non-binary gender terms, which eventually became natural in the story room. Nobody questioned or found it strange that Cinderella was bisexual or gay in others' stories, embracing terms naturally as they should be. 
Surprisingly, there were lots of stories that focused only on entertainment rather than on gender itself. "The father wanted his bird to find a cookie. Every puppies in the kingdom was invited including Cinderella!" This display of random placement of words caused much laughter in the chat room. This aspect of entertainment allowed the "Readers" to also enjoy the project. More importantly, it induced the participants' reading of others' stories in general, allowing them to think about the diversity of choices that others made in DIY Cinderella, especially gender roles.

Participants also participated more actively by giving feedback on others' stories. People tended to react more to the funnier ones, like Cinderella getting divorced with the prince. But for stories where Cinderella was MTF Transgender, gay, bisexual, etc., people tended not to react as much. Most comments were simply about how that particular characterization of Cinderella was "creative" or "interesting". From the lack of reactions, we could find that people were not familiar with the various gender terms and feared giving the wrong impression regarding the sensitive matter. This exemplified the concept of sexual stigma, in which, "members of society know that homosexual behaviors and attractions are devalued relative to heterosexuality" (Herek et al, 2009). Moreover, we could witness some of the stereotypes people had within the chat room, although most people enthusiastically contributed to expanding the diversity of stories and breaking such stereotypes.

\section{CONCLUSION \& LIMITATIONS}

Although we were satisfied with the project and its results overall, we felt there were some limitations. The first were the constraints imposed by the format of the program itself. Through restricting the extent to which the participant can change the story, and the examples provided to assist in showing what kind of words (nouns, descriptions of characters, etc.) should be inserted, our own values were inevitably connoted which could have lessened how creative the participants could be in their recreations. Plus, there was the problem of accessibility due to the program being in the form of Python and also English, which was difficult for some Koreans. Also, we were regretful that we could not handle more inequalities or problems that the story of Cinderella does not encompass. Yet, we are certain that through our program, we were able to create a method through which people could realize and change their views on gender roles with the concept of diversity.

\section{REFERENCES}

Haase, D. and Primeau, M., 1993. The Reception Of Grimms' Fairy Tales. pp.120 121.

Herek, G., et al, 2009. Internalized stigma among sexual minority adults: Insights from a social psychological perspective. Journal of Counseling Psychology, 56(1), p.2.

Steinzeig, Aleah E., 2012. Waiting for Prince Charming: Gender Expectations in the European Fairy Tale. Humanities Capstone Projects. 12.

Toomeos-Orglaan, K., 2013. Gender Stereotypes in Cinderella (ATU 510A) and The Princess on the Glass Mountain (ATU 530). Journal of Ethnology And Folkloristics, 7(2), pp. 49-64.

Veselá, A., 2014. Gender Stereotypes In Fairy Tales. Masaryk University, Faculty of Education.

Yolen, J., 1977. America's Cinderella. Children's Literature in Education, 8(1), pp.302-303. 